\title{
A negociação da intimidade, dez anos depois Entrevista com Viviana Zelizer
}

\author{
Por Nadya Araujo Guimarães, André Vereta-Nahoum, \\ Federico Neiburg e Bianca Freire-Medeiros \\ Tradução de Eny Vereta-Nahoum
}

No dia 8 de setembro de 2015, gentilmente acolhidos por José Sergio Leite Lopes no Colégio Brasileiro de Altos Estudos da Universidade Federal do Rio de Janeiro, reunimos um pequeno grupo de intelectuais brasileiros para rememorar, com Viviana Zelizer, os seus principais passos na construção do festejado livro The purchase of intimacy, bem como os desdobramentos a que a publicação deu lugar no campo da sociologia econômica. A entrevista contou com a participação de Nadya Araujo Guimarães (USP-Sociologia/CEM-Cebrap), André Vereta-Nahoum (Fapesp/Cebrap), Federico Neiburg (NuCEC/UfRJ) e Bianca Freire-Medeiros (USP/Sociologia).

Poucas horas depois da gravação, uma plateia sequiosa ouviria a conferência proferida por Zelizer sobre The purchase of intimacy e as novas sendas abertas pelo livro na sua sempre desafiadora agenda. Era um evento comemorativo dos dez anos de lançamento da obra, que veio à luz em 2005, pela Princeton University Press. A celebração teve o patrocínio do Núcleo de Cultura e Economia (NuCEC) do Museu Nacional da Universidade Federal do Rio de Janeiro. À conferência de Viviana Zelizer, seguiram-se duas reflexões em contraponto, por Federico Neiburg e Nadya Araujo Guimarães, e um animado debate.

O tom da entrevista que a Tempo Social faz circular neste Dossiê ganha sentido se a situarmos nesse clima de reflexão intelectual, a um só tempo densa e amistosa. Como editores, havíamos decidido deixar Viviana Zelizer livre, até mesmo para melhor usufruirmos do brilhantismo da sua reflexão. Por isso mesmo, fizemos chegar-lhe previamente uma lista bastante sumária de meia dúzia de pontos, que seriam 
cobertos da maneira e na sequência que melhor lhe aprouvesse. Para valorizar seu relato, no momento da edição da entrevista tão somente ordenamos o fluir do seu discurso conforme os grandes temas pelos quais se desdobrou a narrativa, evitando fragmentá-la segundo as perguntas que se agregaram no transcurso da gravação.

O resultado é uma rica reflexão, que toma em perspectiva seja a construção da obra, seja a trajetória profissional da sua autora, seja os novos desafios por onde segue, hoje, a sua agenda. $\mathrm{O}$ tom fortemente reflexivo de Zelizer ilustra "as aventuras da pesquisa", para usar as palavras da entrevistada. Esse misterioso processo que, via de regra, passa despercebido ao leitor, quando se defronta com o outro mistério, o de desvendar uma obra - pronta, completa, publicada -, "como se tudo tivesse sido planejado desde o início..., dirá Zelizer.

Uma boa leitura!

Nadya Araujo Guimarães e André Vereta-Nahoum (editores)

The purchase of intimacy: os caminhos da sua produção

Para pensar em perspectiva o caminho até a produção do livro The purchase of intimacy, teríamos que começar tratando do meu interesse pelo tema dos sentidos sociais do dinheiro ou, como disse em outra ocasião, "minha obsessão pelo dinheiro". Tudo começou com a minha preocupação a respeito dos modos de atribuir valor às vidas humanas, antes que com uma preocupação teórica quanto à natureza do dinheiro. No meu primeiro estudo sobre os seguros de vida (Zelizer, 1979) ${ }^{1}$, fiquei intrigada com a forte resistência ao que muitos consideravam como o profano "dinheiro da morte" e com o modo como, entretanto, esse dinheiro ganhara legitimidade, na medida em que passou a ser parte das novas concepções acerca da morte. Em seguida, no meu livro sobre as mudanças na atribuição de valor às crianças (Zelizer, 1985), deparei também com acalorados debates sobre o dinheiro das crianças, em especial sobre a invenção das allowances.

Comecei a trabalhar sobre o material para The purchase of intimacy logo após haver publicado meu terceiro livro, The social meaning of money (Idem, 1994). Nele tratara de retraçar a evolução das práticas sociais que acompanharam a generalização das transações monetárias nos Estados Unidos. Pude, então, compreender o paradoxo histórico pelo qual, naquele país, ao mesmo tempo que o Estado agia para conseguir

1. As indicações bibliográficas, a lista de referências ao final e as notas foram elaboradas pelos editores da entrevista. 
instituir uma única moeda nacional, as pessoas estavam continuamente perturbando tal uniformidade monetária, criando todos os tipos de distinções monetárias.

Trabalhar sobre esses materiais empíricos, como se pode ver, levou-me inevitavelmente a levantar questóes mais gerais sobre como o dinheiro funciona. Decidira que deveria investigar em maior profundidade as múltiplas formas do dinheiro, começando pela casa. Uma ideia que, de repente, começou a expandir-se. O plano original compreendia um capítulo sobre presentes, além de três capítulos sobre o dinheiro institucional: um sobre o bem-estar (welfare) e dois outros, que nunca concluí, um sobre o dinheiro na economia dos universitários (estudo que estou fazendo agora) e outro sobre o dinheiro na economia da prisão. Encontrei dados tão fascinantes... e a vida é curta! Então, eu não podia continuar.

Ocorre, entretanto que, de um modo ou de outro, todos esses temas pertencem a economias que são consideradas mais light, por assim dizer, mais leves. Daí porque enfrentei a reação - de certo modo não justificada, conquanto compreensível -, no sentido de dizer: "Bem, isso é tudo muito lindo, mas quando chegamos ao dinheiro sério, àquele do comércio, do mundo mais masculino, aí todas essas coisas desaparecem". Mas, evidentemente, minha intenção não era essa. A intenção, talvez não bem expressa, era enfrentar qualquer dinheiro. Todavia, como meu plano não era estratégico, o artigo que saiu no American Journal of Sociology, antes de vir à luz o livro sobre o dinheiro, chamava-se "The social meaning of money: 'special monies"' (Idem, 1989, pp. 342-377), o que acabou sendo uma armadilha. Isso porque, ao chamá-los de special monies, de certo modo dava a entender que eram distintos, como se houvesse special monies e regular monies. Entretanto, eu não tinha a intenção de dizer isso. Porém, ao mesmo tempo, para mim era interessante chamá-los de special monies, visto que a teoria argumenta que todos os dinheiros são especiais, de forma distinta.

Assim pensando, dei à ideia a forma de um projeto, e concorri a uma [bolsa da Fundação] $]^{2}$ Guggenheim. Antes disso, tivera de assumir a chefia do Departamento por quatro anos, período em que acreditei que não poderia fazer nada mais ${ }^{3}$. Finda a chefia, ofereceram-me a possibilidade de candidatar-me a uma nova posição em Princeton, dessa vez como Decana, Dean of the Faculty ${ }^{4}$. Estavam muito entusiasmados com algumas coisas interessantes que eu havia realizado como chefe do departamento.

2. Tal como nesse trecho, doravante o leitor encontrará outras informações complementares entre colchetes que foram incluídas pelos editores da entrevista, de maneira a completar o sentido de certas passagens.

3. Viviana Zelizer chefiou o Departamento de Sociologia de Princeton University entre 1992 e 1996.

4. Como Dean of the Faculty, Zelizer seria responsável por desenvolver e implementar políticas, acadêmicas e administrativas, voltadas para os docentes e outros profissionais acadêmicos. 
À época eu acabara de publicar The social meaning of money e cogitava sobre os passos seguintes. Pensei na proposta durante duas semanas, e decidi que não podia ser Decana; não era para mim. Preciso de dias em que não quero ver ninguém! [Declinei] não por ser algo tedioso, mas porque afinal havia preparado aquele projeto [para a Guggenheim] e queria colocá-lo em marcha 5 . Passei, então, um ano [acadêmico, 1996-1997] no Instituto de Altos Estudos [Institute for Advanced Studies] em Princeton, às voltas com o projeto que se chamava Payments and social ties.

A ideia do projeto era justamente fazer um estudo sobre os salários, a determinação social dos salários e a determinação social dos pagamentos discricionários, como os bônus, esse tipo de "extras". Contei também com uma pequena bolsa, concedida pelo Citibank num período em que era dirigido por um presidente especialmente lúcido, John Reed, responsável por criar uma certa quantidade de dotações para ciências sociais ${ }^{6}$. Era uma bolsa muito pequena, mas que me permitiu começar a estudar disputas no Citibank sobre os bônus; disputas em torno de quem paga a quem. Então, eu tinha um pouco [de material empírico] reunido; havia, até mesmo, ido àquela torre que caiu, o World Trade Center, onde eles tinham seus escritórios. De um modo ou de outro, eu já tinha algo sobre o tema. Além dos salários e dos pagamentos discricionários, havia uma terceira parte no projeto sobre pagamentos íntimos. A questão era, então, comparar três sistemas - salários, pagamentos discricionários e pagamentos íntimos - que parecem muito distintos, de modo a observar se neles encontraria princípios similares, relacionais, que estivessem em jogo. Assim, pretendia demonstrar que não é somente no domínio do íntimo que esses princípios se fazem presentes, e que, portanto, eles podem ser também utilizados para compreender os pagamentos mais comerciais, aqueles que têm lugar até mesmo no centro do capitalismo, como no Citibank.

A essa altura eu estava acumulando material sobre o que mais me interessava: a questão dos bônus. De fato, no livro sobre o dinheiro [The social meaning of money] já havia uma pequena parte sobre como emergira o que se denomina de "Christmas bonus”, os bônus pagos no Natal. Havia também toda uma seção que refletia sobre esse tipo de pagamento e por que não o incluíam no salário. Em casa, eu reunira uma importante quantidade de documentos históricos, e tudo isso já se estava acumulando no Instituto naquele ano [o ano acadêmico de 1996-1997]. De repente, algo inesperado aconteceu. Alguém que estava organizando a sessão presidencial da Conferência Anual de Antropologia da American Anthropological Association me

5. A Fundação Guggenheim concedeu a Viviana Zelizer a bolsa como "John Simon Guggenheim Memorial Foundation Fellow” durante o ano acadêmico de 1996-1997.

6. Zelizer refere-se à dotação que recebeu do Citicorp Behavioral Sciences Research Council, entre 1997 e 2001. 
chama por telefone (não foi Margaret Lock, conquanto ela estivesse na sessão). Era um convite para participar de uma sessão sobre comodificação; e me convidaram porque conheciam o meu trabalho anterior, sobre as crianças, e não a propósito do trabalho sobre o dinheiro. Lá estaria Arjun Appadurai. Uma sessão fascinante! Que fazer? Ora, do tema das crianças eu já estava aposentada. Porém, eu havia falado um pouco do projeto sobre pagamentos e vínculos sociais na Faculdade de Direito de Miami (onde ensinava meu irmão), ocasião em que veio à sessão um colega que dava aulas sobre impostos. Eu discorria sobre dinheiros, quando ele me disse: "Isso para nós, que estudamos impostos, é fascinante, a diferenciação do dinheiro”. E, não sei como, me ocorreu a ideia desse caso que tenho em The purchase of intimacy - do velho que morre e tem duas irmãs. Isso me pareceu fascinante.

Eu estava também muito interessada pelo tema das chamadas loss of consortium claims $^{7}$. E por que me parecia interessante? As loss of consortium claims aplicam-se, por exemplo, a situações em que ocorrem acidentes, quando uma mulher, ou um marido, se acidenta. No caso, pela lei de "consórcio perdido" (lost consortium) a compensação pode se fazer, e não apenas por danos decorrentes da perda de trabalho, mas também por danos emocionais; ou seja, pela perda de companhia emocional, e até a perda de companhia sexual. Isso é uma coisa muito estranha, porque a lei norte-americana, em geral, não admite compensar por questões ligadas à participação sexual porque seria como compensar a prostituição. Mas nesse caso era legítimo. Então, a minha ideia inicial foi fazer outro estudo histórico.

Ademais, e me havia esquecido de dizer, eu estava começando a acumular uma quantidade de casos relativos a essa lei de consórcio, todos eles referentes ao mesmo período histórico, final do século xIx e início do século Xx. E o estava fazendo bem sistematicamente: pensava em escolher três estados [da Federação] que parecessem interessantes e sobre eles reunir, para esse período, uma seleção de casos. Nunca fiz análises sistemáticas, mas no caso desse estudo seria um pouco mais sistemática. De repente, eu me dei conta de que, primeiro, seria uma quantidade enorme [de casos] para recobrir os três estados ao longo de todos os anos; e, depois, não era isso o que mais me interessava.

7. O termo consortium possui no Common Law um sentido distinto daquele que ganhou nos ordenamentos jurídicos de inspiração romana (Civil Law). Naqueles sistemas jurídicos, consortium refere-se à "associação conjugal de marido e esposa, e o direito de cada um à companhia, cooperação, afeto e apoio do outro em toda relação conjugal [...]. O termo inclui o direito exclusivo aos serviços do cônjuge, e à sua sociedade, companhia e afeto conjugal" (Consortium, em Black, 1968, p. 382). A aplicação do termo estava ligada aos serviços da vida doméstica que podiam ser esperados pelos cônjuges (inicialmente apenas maridos, mas depois também esposas) e, em decorrência, ao direito de obter reparação judicial contra qualquer um que impossibilita o cônjuge de prestá-los ou contra o próprio cônjuge que falha em suas obrigações domésticas. 
Bem, perdão porque me desviei, mas as informações ajudam a entender o rumo dos acontecimentos. Retomo: recebera esse convite para o Congresso de Antropologia. E já estava pensando, além dos bônus, em fazer um estudo sobre as leis de consortium. Assim, pensei que poderia escrever algo pequeno, coisa que em geral não faço. Mas a oportunidade era tão irresistível, pelo tipo de participante que estaria na sessão, que decidi tentar fazer um trabalho que não era bem ao meu estilo; e o fiz. $\mathrm{O}$ debatedor da sessão era John Comaroff ${ }^{8}$. Eu não o conhecia. Era uma sessão incrível. John Comaroff ficou muito interessado pelo trabalho. Ele era um dos editores do Journal of Law and Social Inquiry, que é interdisciplinar, e me disse que eu tinha que lhe mandar esse artigo, ao que respondi que aquilo ainda não era um artigo. Bem, acabei por escrever o artigo. A editora, Carol Heimer, era, por acaso, alguém que eu conhecia muito bem; uma reconhecida socióloga da Northwestern [University]. Pediram-me mudanças muito mais sérias, bem mais dramáticas do que me havia sido solicitado no caso dos meus artigos publicados no American Journal of Sociology. Já não me lembro o que era [solicitado]. Mas eram tão sérias que as deixei de lado e continuei a fazer as outras coisas em que estava envolvida. Algum tempo depois decidi retomar e fiz as alterações. Foi quando percebi que aquilo me divertia muito mais que a questão comercial, e decidi me desviar do projeto sobre pagamentos. Percebi, ademais, que era algo que podia fazer. Claro que demorei anos! O livro [The purchase of intimacy] demorou algo como dez anos, o que se justifica porque muitas outras coisas estavam acontecendo.

De toda sorte, do ponto de vista teórico, acabei por não continuar com a intenção de, no novo livro, demonstrar que esse tipo de análise se aplicaria também ao outro mundo, o do coração do capitalismo. Outros estão fazendo esse trabalho, hoje, utilizando o modelo. Entretanto, eu diria que, em geral, The purchase of intimacy inspirou trabalhos de autores mais jovens, mas sobretudo dentro desse mesmo terreno.

Desdobramentos analíticos a partir de The purchase of intimacy: avançando na noção de "trabalho relacional"

Passado algum tempo, já depois que eu havia publicado Economic lives (2010), outro fato totalmente aleatório teve lugar. O acontecido lembra o que Chuck Tilly [Charles Tilly] nomeara como "cotovelos invisíveis", em vez de mão invisível, para aludir aos processos que têm lugar quando há erros e o desafio é corrigi-los?.

8. John Comaroff, antropólogo sul-africano, é professor dos Departamentos de Estudos Africanos e Afro-Americanos e de Antropologia na Harvard University, sendo internacionalmente celebrado por sua importante produção no campo dos estudos coloniais e pós-coloniais.

9. A metáfora do "cotovelo invisível" aparece intitulando o artigo "Invisible elbow" publicado por Charles 
No meu caso, não se tratava propriamente de corrigir erros, mas, antes, rumos, que eram, aliás, totalmente aleatórios. Nesse sentido, outro acontecimento imprevisto ocorreu, creio que em 2009. Nesse ano, entrou em contato comigo Fred Block (que agora se aposentou da Universidade de Califórnia, Davis), um sociólogo político, macro, que escreveu recentemente um excelente e bem recebido livro, com Margaret Somers, sobre Polanyi, editado por Harvard (Block e Somers, 2014). Block - uma pessoa bastante capaz, que eu conhecia muito pouco, com quem havia cruzado apenas uma ou duas vezes, ou seja, que era de outro mundo, já que lidava com política, com grandes coisas, que não são meu mundo - escreveu-me um e-mail em que dizia que recentemente havia utilizado The purch ase of intimacy em seu curso para alunos de pós-graduação, e que o conceito de relational work, de trabalho relacional, the parecera algo que realmente poderia imprimir um rumo distinto ao conceito de embeddedness (enraizamento), à vertente mais tradicional da Nova Sociologia Econômica, que aliás já está velha, mas que foi nova em algum momento. Na ocasião, ele me disse que esse tema o entusiasmava e que gostaria de organizar uma pequena conferência em UC Davis [University of California, Davis], reunindo gente jovem. Eu não podia dizer que não, porque me pareceu incrível.

Esse era também um conceito sobre o qual eu havia discutido muito com Chuck [Charles Tilly]. Ninguém sabe, mas tive uma amizade muito apreciada e mágica com Charles Tilly, que também vinha de seu mundo estrutural. Nós nos conhecemos na Russell Sage Foundation e tivemos um diálogo totalmente mágico ${ }^{10}$. Foi uma influência recíproca. À época, eu já estava feita, mas ele me influenciou muito. Foi uma experiência especial conhecer alguém tão maravilhoso, ter o privilégio de conhecer gente com luz, com generosidade total e aprender como ele era com os alunos, os conselhos que ele dava. Tive a oportunidade de ser testemunha disso. Era alguém especial. Tinha a capacidade de fazer o trabalho e de dar, o que nem sempre é possível. Ele ficara muito entusiasmado com o conceito de trabalho relacional, que lhe parecia fantástico.

Eu teria abandonado essa ideia, depois de escrever The purchase of intimacy, não fora o convite de Block, que me levou a pensar "preciso escrever algo". Em geral,

Tilly em Sociological Forum (1996, pp. 589-601). Assumindo que a interação social envolve um recorrente processo individual de errar e corrigir erros, Tilly propõe, nesse artigo, que a ordem nas estruturas e nos processos sociais resulta, não da "mão invisível" que conduz a ação racional, mas dos constrangimentos que se interpõem aos indivíduos nesse incessante processo de corrigir erros (e que operam como “cotovelos invisíveis", p. 593). Tais constrangimentos são estabelecidos seja pelo modo como representamos os entendimentos compartilhados que historicamente acumulamos (pela cultura, dito de forma mais simples), seja pelas relações sociais previamente estabelecidas.

10. No ano acadêmico de 1987-1988, Viviana Zelizer e Charles Tilly conviveram como visiting scholars do programa da Russell Sage Foudation. 
escrevia apenas livros. Concentrara-me em escrever livros e os três primeiros eram teóricos. Mas pensei que a ideia era linda e que seria uma coisa incrível desenvolvê-la. Houve, então, uma pequena conferência, que Block organizou em UC Davis com os alunos $^{11}$. Mais recentemente, vários entre os participantes da reunião em UC Davis organizaram a conferência sobre o dinheiro, da qual também participaram outros colegas e alguns alunos mais antigos ${ }^{12}$. Para a reunião em Davis, tive que escrever o artigo que se chama "How I became a relational economic sociologist and what does that mean?". Os trabalhos apresentados foram, em seguida, publicados em uma edição especial, dedicada ao tema do trabalho relacional, da revista Politics \& Society, de cuja editoria participava Block ${ }^{13}$. Isso foi também totalmente insólito, e me forçou a avançar na reflexão, o que me custou muito, até porque aprofundar o conceito de relational work não era algo que eu estivesse cogitando fazer.

$\mathrm{O}$ conceito agora tem pernas próprias. Um aluno mais jovem, que está terminando [seu doutorado], Alfredo García, escreveu uma revisão crítica de vários trabalhos - e há muitos trabalhos - que estão utilizando o conceito de relational work, bem como entrando na questão dos circuitos (García, 2014, pp. 639-647). O texto foi publicado por uma revista on-line (que eu não conhecia e não sei quem a organiza) chamada Sociological Compass; compass, no sentido de bússola. Uma revista interessante, que publica resenhas de conceitos e balanços de literatura e tem coisas bastante boas ${ }^{14}$. Nina Bandelj, socióloga, ensinando em Irvine [University of California, Irvine] ali publicou, em seguida, uma resenha sobre Hostile worlds juntamente com alguns de seus alunos (Bandelj, Morgan e Sowers, 2015, pp. 115-127).

Faço aqui um parêntese. Nina Bandelj é minha aluna adorada, e me escreveu hoje me recordando: "Eu sei que você vai falar hoje..." Mas essa é outra história, a da conexão com os alunos. Há afetos que podemos antecipar, tais como o que

11. A "Relational Work Conference" aconteceu em $1^{\circ}$ de maio de 2010, na UC Davis, sob a responsabilidade de Fred Block e com o patrocínio da Politics \& Society e da Graduate School of Management. O objetivo era explorar as potencialidades abertas pelo uso do conceito de "trabalho relacional", tal como desenvolvido por Viviana Zelizer e Charles Tilly para o entendimento de diferentes situações de mercado; nesse sentido, os papers apresentados exploraram domínios empíricos tão diversos como doação de óvulos, colaborações universidade-indústria, governança na internet, papel do governo na mercantilização da terra e relações de subcontratação na indústria pesada.

12. Viviana Zelizer refere-se ao "Money Talks Symposium”, que ocorreu em 12 de setembro de 2014 na Yale University, organizado por Nina Bandelj, do Departamento de Sociologia da University of California em Irvine, Daniel Markovits, da Yale Law School, e por Frederick F. Wherry, do Departamento de Sociologia da Yale University.

13. Trata-se do dossiê temático intitulado "Relational Work in Market Economies", editado por Fred Block, que circulou na Politics \& Society, 40 (2012), e que veiculou o texto de Viviana Zelier nas páginas 145-174.

14. Ver link para a revista em http://onlinelibrary.wiley.com/journal/10.1111/(ISSN)1751-9020. 
resulta do casamento; ou o afeto dos pais, dos avós. Afetos, enfim, que, quando se tem sorte, eram previsíveis. Nunca esperei estabelecer este tipo de relação de afeto com uma enorme quantidade de meus alunos... Mantenho ótimas conexões com muitos alunos, mas com um pequeno grupo deles criou-se mais: um afeto, o que para mim é muito importante.

Retomo. Nina Bandelj preparou a resenha sobre Hostile worlds com seus alunos, e Alfredo García focalizou os usos da noção de relational work. Alguns aplicaram [o conceito] fora da esfera dos temas mais íntimos, do lar, estendendo-o para tipos de trabalho relacional que existem em centros do capitalismo, no comércio por exemplo. Isso é algo que está acontecendo [o uso ampliado do conceito]. Claro que tudo isso é muito limitado. Não é como se o mundo estivesse sendo revolucionado por esse conceito! Entretanto, dentro do nosso mundo limitado, há uma corrente através da qual essas coisas estão se transmitindo. Há um trabalho recentemente publicado em Gender \& Society, de alguém que não conheço, mas do qual fui uma das avaliadoras. Sua autora é uma mulher, e creio que está na Califórnia ${ }^{15}$. Ela escreveu sobre as doulas, as mulheres que auxiliam nos partos, e que agora são pagas também. E também sobre as conselheiras de lactância (breast feeding). Fez uma tese sobre isso e usa o trabalho relacional para entendê-lo. Isso também é totalmente inesperado ${ }^{16}$.

Dizer "trabalho relacional" pode ser algo muito anódino, carente de interesse, porque, em sociologia, todos nós estudamos esse trabalho. Entretanto, o que desenvolvi em meus estudos é algo muito mais específico. Refiro-me à combinação de certas relações com certas transações econômicas, com certos tipos de moedas, com certos significados. E a negociação entre essas quatro ou cinco (dependendo de como queiram definir) dimensões, presentes em qualquer vida econômica, é o que se destaca como interessante. Não se trata de simplesmente dizer que há trabalho relacional. De fato, há vários outros artigos que usam o trabalho relacional como mais um ponto. Mas apenas isso não avança nada, a menos que o tema abordado possa ter sido tão interessante que o conceito (limitado) não importe, isto é, se a parte empírica for muito interessante. Mas isso não é o que me interessa.

Não é apenas isso o que me interessa, por exemplo, nesse trabalho que estou fazendo agora, muito lentamente ( por coisas da vida), nos campi, entre estudantes, sobre a vida econômica desses estudantes. Aqui, de novo, me interessa como, para certas relações entre os alunos, se definem os tipos de transação... se não estão vendendo

15. Trata-se de Jennifer Torres, autora que, ao momento da publicação, estava, não na Califórnia, mas integrada ao Michigan Public Health Institute.

16. Zelizer refere-se ao texto de Jennifer Torres, "Expertise and sliding scales: lactation consultants, doulas, and the relational work of breastfeeding and labor support" (Torres, 2015, pp. 244-264). 
coisas, como é que pagam... Ou seja, trata-se de compreender o mundo econômico usando esse conceito de trabalho relacional; e também o de circuitos.

\section{Os desafios metodológicos}

Tudo o que lhes disse antes sobre meus livros, no que concerne à parte metodológica, eu aprendi em Columbia, onde fiz meus estudos de pós-graduação ${ }^{17}$. Aprendi com um dos professores que tive, um de meus orientadores, que se chamava Sigmund Diamond. Ele era formado em Harvard como historiador. Tinha um doutorado em história e jamais havia seguido um curso de sociologia. Essa é uma história muito interessante, cujos detalhes já não lembro. O que importa é que [Robert] Merton e [Paul] Lazarsfeld, os dois famosos sociólogos de Columbia, trouxeram-no para ensinar o que se chamava "análise documental", e que hoje se chama "sociologia histórica”. Mas ele nos ensinou análise histórica de um modo muito tradicional, não como se ensina atualmente sociologia histórica em qualquer curso de um departamento de sociologia nos Estados Unidos. Era muito tradicional. Eu aprendi com ele, e assim comecei, na minha tese sobre seguros, fazendo análise de documentos, com as fontes e com análise qualitativa. Nunca fiz codificação (coding), por exemplo. Fiz meu próprio coding, um coding doméstico. Isto é, ler, ler tanto até que começa a repetir-se. Foi assim para a pesquisa sobre o seguro de vida, que está na tese e depois no primeiro livro; e embora haja um livro sobre seguros que conta algo distinto, à época, esse [Morals and markets] ainda é um livro que se usa. As pessoas que estão interessadas nesse tipo de coisas ainda o utilizam. Ele não foi desqualificado. E não é porque tenha ido a arquivos em todo o mundo, em todos os Estados Unidos. Concentrei os esforços e obtive resultados.

Outra questão que foi emergindo metodologicamente com os primeiros livros foi o foco nos conflitos ao estudar significados culturais, isto é, centrar-se nos conflitos. Quando fui estudar seguros de vida, encontrei conflitos. Não decidi estudar o seguro de vida porque havia conflitos. Depois percebi que tinha caído no estudo de conflitos, sobretudo com temas históricos, porque há documentos. Metodologicamente, é algo para se prestar atenção, os conflitos. Por exemplo, em torno do trabalho das crianças. No livro das crianças [Pricing the priceless child], a primeira coisa que me interessava era o tema dos seguros, porque havia visto uma pequena nota que dizia que teria ocorrido um grande conflito em torno de assegurar a vida das crianças, em princípios do século xx. Então eu disse para mim mesma: "Isso é interessante". Também consegui dados

17. Depois de se graduar na Rutgers University, em 1971, Viviana Zelizer obteve o seu MA por Columbia em 1974, onde também se titulou phD em 1977. 
de uma bibliotecária numa empresa de seguros e assim começou esse livro. Pensei que aquilo era interessante. $\mathrm{E}$ ao fim, terminei o livro e pensei que devia ter algo sobre o trabalho infantil. Os primeiros capítulos foram escritos depois que terminei o livro. Isso é outra coisa que ninguém imagina, que alguém escreva uma introdução antes dos capítulos. E o livro do dinheiro também. Porque a parte mais geral do livro, que não é sobre a diferenciação, trata do paradoxo de que o Estado norte-americano estava estabelecendo essa moeda única e, ao mesmo tempo, produziam-se todas essas diferenciações. Nesse momento é que me dei conta de que aquilo era um interessante paradoxo. E terminei por escrever sobre isso no capítulo inicial.

Ademais, hoje me dou conta de que tanto o livro sobre o seguro [Morals and markets] como o livro sobre as crianças [Pricing the priceless child] e o livro sobre o dinheiro [The social meaning of money] têm uma espécie de coragem que é típica da juventude, de quando somos mais jovens. Por quê? Porque agora sei mais, e de certo modo posso aconselhar melhor. Mas também me dou conta dos meus limites. Por exemplo, hoje quando revejo sobretudo o livro dos meninos [Pricing the priceless child], em que digo que há uma mudança histórica total no valor das crianças, com os casos legais - e isso foi publicado, saiu! Sobre ele, foram feitos três encontros de discussão e houve uma seção que saiu numa revista, Journal of the History of Childhood [and Youth], na qual escreveram alguns historiadores muito bons, tratando do papel desse livro ${ }^{18}$. E me pergunto: mas, como? Conto isso porque creio que é útil, sobretudo, para os jovens. Eu vejo isso entre meus alunos, que pensam que eu já sabia tudo, que eu tinha tanto brilhantismo e que sabia tantas coisas, que sabia como fazer as coisas, que não tinha dúvidas, e assim o fiz e saiu tudo como esperado. A história é muito diferente, porque não a conhecem.

Na verdade, sempre me esforcei muito, mas também sempre fiz tudo com grande prazer. Isso me lembra a lição de minha mãe. Para ela, como dizia, se eu tinha de fazer algo era por ser uma coisa linda para se fazer, porque é uma vida linda para fazer. Se não der certo, dizia ela, faça outra coisa, mas não comece a competir, a se guiar pelo que fazem os outros. Foram conselhos vitais para o princípio da minha vida. Foi assim quando decidi deixar o meu primeiro emprego, que era em Rutgers [University], em Nova Jersey, muito perto de onde eu vivia e tinha meu filho pequeno, em troca de uma oferta para ir a Barnard [College] e Columbia [University]. O lógico teria sido não aceitar. Nessa decisão, foi tremenda a influência de minha mãe, falando por telefone, de Buenos Aires, e na época era difícil falar ao telefone! Em Rutgers

18. Zelizer refere-se ao fórum-retrospectiva sobre Pricing the priceless child organizado por Søland e Bruce (2012, pp. 445-484), com artigos de Paula Fass, Michael Katz, Daniel Cook, Barrie Thorne, Linda Gordon, além da própria Zelizer e de uma abertura de autoria de Søland. 
eles me asseguravam que conseguiria a estabilidade (tenure), porque já ia sair o livro da tese. Entretanto, decidi mudar, não porque o Departamento [de Sociologia] de Rutgers não fosse bom, mas porque tinham interesses distintos dos meus. E olhe que, quando eu estava indo para Columbia, um professor de lá, a quem não haviam dado tenure, disse-me que eu não devia ir, que aquilo lá era um "cemitério de professores assistentes". E quando lhe fui dizer "decidi”, ela [minha mãe] afirmou: "Vá! E se não conseguir a posição permanente, você faz outra coisa”. Aparentemente, [minha decisão de deixar Rutgers] era uma loucura. Eu tinha um filho de sete anos. Mas, se ela não me houvesse dito essas coisas, eu não teria mudado. Mostra a dependência... Eu tinha uma amizade muito positiva com minha mãe.

Ao mudar, passei a estar engajada nas duas instituições, Barnard [College] e Columbia [Universidade]. Em Barnard, que era a seção de mulheres de Columbia, ia ser chefe de departamento. E eu não queria ser chefe de departamento. Queria continuar dando aulas, fazer minhas coisinhas, e não estava muito engajada no mundo profissional. Nesse momento, fazia meu trabalho e depois voltava para ficar com meu filho, porque eu gostava. Em 1987-1988, decidi sair de Columbia e recebi a oferta para trabalhar em Princeton [University], onde fui chefe de departamento entre 1992 e 1996.

Mas, voltando às mudanças metodológicas... Termino o livro do dinheiro [The social meaning of money], que cobriria o mesmo período histórico, e, de repente, percebo com a Negociação da intimidade que não havia sentido em continuar com isso, já que eu estava tentando enfatizar ou concentrar-me num argumento mais amplo, mais teórico, para o qual não necessitava disso. Não me lembro bem de todas as etapas, mas então decidi que me interessava muito mais a parte legal, das mudanças legais, movida pelo tema das leis de consortium. Pouco a pouco fui desenvolvendo o tema, mas desviei, de sorte que a parte original do livro, além do argumento, é a pesquisa legal. Tratei de utilizar o mesmo tipo de análise qualitativa de muitos casos. Como antes, escolhi estrategicamente casos que eram importantes no período histórico e casos que eram interessantes. Também procurei conselhos, consultei professores de direito. Porque, embora eu tenha cursado um ano de direito em Buenos Aires [na Universidade de Buenos Aires], isso não tinha nada que ver [com o que estava fazendo]. Eu escrevera, para o livro das crianças [Pricing the priceless child], um capítulo sobre a compensação de danos quando morrem as crianças e ali havia uma parte legal; ou seja, eu já fizera análise legal. Mas no caso do Purchase of intimacy havia muito mais a fazer. Então, aconselhei-me com gente muito capaz e, ao final, pedi a um colega em Princeton, que faz história legal, para que lesse o livro todo. Passei muito tempo tratando de me assegurar de que isso estava bom. Eu já tinha um pouco de intimidade com esse meio, pois meu pai foi advogado até a sua morte... 
ele ia ao escritório até que morreu aos 92 anos. Era apaixonado pelo direito. Então, e também por isso, me era significativo falar nas faculdades de direito.

Outro aspecto interessante. Quando saiu o livro do dinheiro [The socialmeaning of money], recebi cartas de Cass Sunstein ${ }^{19}$ e de outros professores, especialistas em assuntos legais, muito capazes, que estavam tratando de criticar o movimento do Law and Economics, de Richard Posner ${ }^{20}$. Alguns deles estavam em Chicago. Então, o livro do dinheiro [The social meaning of money] lhes propiciou uma forma de falar do dinheiro de maneira distinta à de Richard Posner. Ademais, o tipo de pesquisa que eu fazia era mais cômodo para eles que o trabalho dos outros sociólogos da economia, de natureza muito mais quantitativa, que a esses juristas não interessava.

Ao mudar a minha metodologia de trabalho, estabeleci outras conversações interdisciplinares. E mais ainda agora, com o projeto que estou fazendo, no qual, pela primeira vez, trato com gente que não está morta. Isto é, pela primeira vez fiz entrevistas, no caso com alunos, o que é uma aventura muito especial. Creio que me é mais custoso, porque, quando me defronto com as entrevistas, procuro enfrentá-las como se fossem documentos históricos; vou apresentar parte disso na conferência de hoje $e^{21}$. Há uma maneira de tratá-las como uma espécie de “rumor”, que se está falando de gente que te contou suas histórias... e isso é diferente de falar dos mortos. Evidentemente, estou segura de que vocês todos são especialistas nisso, e sabem do que estou tratando. Sempre me choca quando alguém faz uma apresentação com base em entrevistas e as transforma em algo cômico. Quero dizer, eu trato [entrevistas] como algo muito precioso. Ao mesmo tempo, os jovens que entrevistei estavam muito interessados. Espero conseguir êxito, mas me tem sido bem custoso.

Estou pensando, neste momento, em preparar apenas um artigo. Tenho feito conferências que são quase um artigo, mas não sinto que já tenha um artigo. E estou tratando o material, também, como um exemplo do que chamo de "circuitos de comércio". Ademais, no curso do trabalho, por conta das entrevistas que já realizei, resultou que eu me concentro sobretudo em um grupo de alunos mais ricos. O que acontece em Princeton e em outras faculdades privadas norte-americanas desse tipo é que estão se misturando mundos totalmente opostos e em um contexto democrático, isto é, com intenções democráticas. Então, como se administram as relações inter-

19. Cass R. Sunstein é o fundador e diretor do Programa de Economia Comportamental e Políticas Públicas da Harvard Law School, e por várias décadas foi professor de direito na University of Chicago.

20. Richard A. Posner, professor na Universidade de Chicago, lançou as bases do movimento Law \& Economics com o seu livro Economic analysis of law (1972). Trata-se de uma corrente de pensamento jurídico segundo a qual os processos legais devem produzir a mais eficiente alocação de recursos.

21. Trata-se da conferência que Zelizer iria proferir logo em seguida, no Colégio Brasileiro de Altos Estudos, da UFRJ, abrindo o evento em comemoração aos dez anos de The purchase of intimacy. 
pessoais entre, por um lado, esses jovens de famílias muito poderosas e, por outro, um grupo de alunos que têm assistência financeira total? Em Princeton, como em outras faculdades desse tipo, 60\% [dos alunos] têm apoio econômico da faculdade; a maioria deles vem de famílias que têm dinheiro, mas que igualmente podem ter apoio econômico. Há uns duzentos alunos por ano - não tenho o número exato aqui, mas digamos duzentos por ano - que vêm de famílias realmente pobres e que têm apoio econômico total, ainda que muitos também trabalhem. Parte do projeto é compreender o que significa o trabalho dentro da Universidade. Isso porque em Princeton, como em outros campi, os estudantes trabalham em uma ampla gama de atividades: nos serviços de restaurante e na biblioteca, mas também como voluntários pagos para experiências em psicologia, entre outras tarefas. $\mathrm{O}$ trabalho exercido durante os estudos de graduação levanta um conjunto de questões sobre o tema do trabalho que raramente tem sido explorado, mesmo por especialistas em assuntos laborais. Cabe indagar-se: Em que medida a missão educacional da faculdade se realiza na circunstância do emprego estudantil? Que tipos de trabalho são definidos como apropriados para os alunos, para que tipo de alunos e para que momento na trajetória dos mesmos? Além disso, uma vez que o trabalho com frequência leva a que alunos estabeleçam interações do tipo trabalhador-cliente com outros alunos, como essa relação dupla e desigual é gerenciada?

Tratei desse tema na conferência sobre o dinheiro em Paris ${ }^{22}$. Entretanto, pedi a Florence [Weber] ${ }^{23}$ que não colocasse o vídeo na internet, porque ainda não estou me sentindo cômoda para dar às ideias uma forma escrita; ainda não está maduro.

No trabalho que estou fazendo, o mais interessante é que tenho citações não apenas de alunos, mas também de ex-alunos; por exemplo, David Stark, famoso sociológo economista que falou comigo e que foi aluno há muitos anos. Ele foi beneficiário de auxílio financeiro e trabalhou servindo aos outros alunos. Atualmente, é diferente como organizam o sistema de refeitório, mas a relação estudante-estudante de repente confunde-se com a relação enquanto trabalhador. Como se negocia isso? Isso é parte do projeto. Isso também apareceu com respeito à situação dos estudantes que são jogadores de futebol americano, que ainda não explorei. São trabalhadores ou são estudantes? Como são pagos? E isso varia.

22. Zelizer se refere à conferência na École Normale Supérieure, entre 29 de junho e $1^{\circ}$ de julho de 2015 , organizada por Florence Weber, Angèle Christin, Agnès Gramain, Sacha Bourgeois-Gironde e Ilka Vari-Lavoisier, na qual se celebrou o vigésimo aniversário de lançamento do seu livro The social meaning of money.

23. Florence Weber, antropóloga francesa, é destacada pesquisadora e autora no campo dos estudos da socioeconomia na França; seus estudos têm explorado a fronteira entre a economia doméstica e a economia de mercado, lançando mão de forma sistemática e refinada do recurso à etnografia econômica. 
No que respeita ao tema dos créditos estudantis e do endividamento das famílias, Princeton é um caso muito especial, como algumas outras universidades. Princeton foi a primeira a eliminar as dívidas. Não porque as tenha passado a tratar como presentes! São doações; eles doam o dinheiro aos alunos. Os jovens, às vezes, contraem pequenas dívidas, para diferentes coisas, mas isso não se confunde com o problema principal, com o grande problema econômico principal, que são as dívidas, evidentemente. Compreendê-lo não é objeto do projeto, entretanto. Isso é, por assim dizer, mantido constante; não entra na análise. Entra, sim, e é fascinante, a relação desses jovens que têm ajuda financeira com seus pais, porque, em muitos casos, os jovens lhes enviam dinheiro.

\section{Desdobramentos e novos usos das ideias veiculadas em The purchase of intimacy}

Há ainda outro aspecto que creio ser interessante destacar e que está documentado em um trabalho que fiz depois, e que circulou como um pequeno artigo. Nele trato do outro lado da negociação da intimidade.

Em The purchase of intimacy mostrei o que acontece quando, nas relações íntimas, entram questões econômicas. Entretanto, faltava o inverso: o que acontece quando, nas organizações, entram relações pessoais, sejam de amizade, sexuais ou os negócios de família. Ou seja, como se administra isso? Muito pouco se estuda a respeito e, em geral, a ideia é que se trata de algo negativo e perigoso; pela mesma razão que se pensa que é negativo e perigoso haver coisas econômicas nas relações íntimas. Escrevi, então, um pequeno trabalho que foi publicado num livro editado por Nina Bandelj, minha aluna eslovena que é professora titular em Irvine, há bastante tempo, uns três ou quatro anos (Zelizer, 2009, pp. 23-55). Nele há todo um terreno de possível exploração, que creio seja importante considerar.

Vale mencionar também um outro desdobramento das ideias que formulei, por ser o mais inesperado. Chegaram-me vários artigos, um de uma socióloga e outro de uma antropóloga, cujo nome não recordo, que estão fazendo estudos sobre Aids em Malawi. Nesse país, os jovens mantêm trocas monetárias e sexuais, que não são consideradas prostituição, diferenciadas da prostituição. Isto é, relações românticas em que o homem, jovem, dá à mulher, à jovem, dinheiro como expressão de seu afeto, às vezes depois da relação sexual, coisa totalmente tabu. Então, a ideia dos pesquisadores da Aids é que, se as jovens recebessem microcréditos, ou alternativas para obter dinheiro, que não a dos seus namorados, ou seja, se lhes dessem outra fonte de renda, iriam ter menos relações sexuais e haveria menos Aids. Ainda são controversos os resultados. Entretanto, alguns desses estudos encontraram que [essa política] desconsiderava que o dinheiro que lhes era dado pelos namorados era uma expressão de 
afeto e, logo, [a política] não funcionava. Michelle Poulin, uma socióloga, pesquisou o tema e depois escreveu sobre isso com Iddo Tavory, um jovem e brilhante sociólogo israelense que agora está na NYU [New York University] (Tavory e Poulin, 2012, pp. 211-231); e há ainda uma antropóloga, cujo nome não recordo. Tudo isso para mim foi uma surpresa, porque nunca poderia ter imaginado um desdobramento da Negociação da intimidade para tratar de influenciar a política de Aids em Malawi.

\section{A recepção e as críticas}

Não, não foram muitas. O debate girou mais em torno do dinheiro.

Houve uma crítica de alguns economistas, que saiu na Economy and Society ${ }^{24}$. Eles argumentam que as diferenciações são, primeiramente, uma consequência de que o dinheiro tem sua universalidade, o que é muito interessante. Também há [críticas] dizendo que as diferenciações são triviais, porque o dinheiro continua sendo dinheiro e, logo, que é muito difícil aceitar a diferenciação. Ora, o que está acontecendo é que, ao contrário do início do século xx (e isso é uma das coisas sobre as quais tenho de pensar um pouco mais, porque os ensaios da conferência que fizemos em Yale ${ }^{25}$ vão sair em um livro ${ }^{26}$, e eu me comprometi a ajudar meus ex-alunos, a Nina Bandelj e o Fred Wherry, professor em Yale, a escreverem uma pequena introdução), quando se estava monetizando tudo, quando o dinheiro avançava com sua parte homogênea, poderosa, era lógico pensar que isso era o principal; e difícil conceituar a diferenciação. O que está acontecendo de certo modo agora é justamente uma enorme diferenciação, física e de uso. Desde o Bitcoin até todos os demais. Há, por exemplo, uma forma de pagamento - para assumir a diferenciação entre modo de pagamento e moeda - que se chama Venmo, utilizada sobretudo pelos universitários e pelos mais jovens, que é uma forma muito fácil de fazer o pagamento. Se vão comer juntos em um lugar, há "venmo you". Trata-se de um aplicativo, que é um sistema de pagamento distinto. Bitcoin é o mais dramático [exemplo], mas há vários exemplos desse tipo de coisa.

A crítica que saiu a respeito do livro do dinheiro [The social meaning of money] no New York Times, por um famoso economista, John Kenneth Galbraith, já falecido, pai também de um economista, foi muito positiva. Já a crítica ao The purchase of intimacy, também no New York Times, foi escrita por um professor de Law and

24. Zelizer refere-se ao texto de Fine e Lapavitsas (2000).

25. Zelizer se refere à Conferência "Money Talks", que teve lugar em Yale em 12 de setembro de 2014, dedicada a celebrar o vigésimo aniversário do seu livro The social meaning of money, organizada por Nina Bandelj e o Frederick Wherry.

26. Zelizer se refere ao livro então em preparo e que acaba de ser publicado, organizado por Bandelj, Wherry e por ela própria, e intitulado Money talks: explaining how money really works (2017). 
Economics de Chicago [Richard A. Epstein], o mais feroz crítico! Incomodou-me, mas não foi terrível.

O que ainda penso é que o fato de não haver feito o livro sobre os vínculos e os pagamentos comerciais, por ter me concentrado nos pagamentos íntimos, limitou, de certo modo, o impacto do que estou fazendo. Eu diria que o impacto do que faço é em parte pela idade, porque estou mais velha, e então sou mais levada em conta. Estou certa disso. Acho que há uma espécie de respeito ao idoso, ao sobrevivente idoso, e ao idoso que tem ideias.

A parte que me dá mais alegria não é o establishment da sociologia econômica, com o qual tenho muito boa relação, mas a repercussão do meu trabalho junto aos mais jovens. A atenção que vejo despenderem, os trabalhos em que vejo usarem bem [meus conceitos], em que há entusiasmo. Isso é parte de minha alegria. A outra parte, que tenho muito clara, é o prazer que me dá esse trabalho; é o agora. Sei que dentro de trinta anos isso pode desaparecer completamente. Sei que mesmo [sobre quem foi] Robert Merton, o grande sociólogo, tenho que explicar a alunos de pós-graduação, porque há alguns que não [o conhecem]... São lições de humildade.

Então, o grande prazer é poder conversar com esses alunos maravilhosos, estar aqui com vocês, ver que há gente que usa isso para compreender melhor o mundo, mas não para a posteridade. Porque, na realidade, Goffman pode ficar... Porque, quando há certos professores famosos que fecham as portas, que dizem não ter tempo, porque estão escrevendo essa coisa tão importante... a escolha é no sentido de que "há que fazer o trabalho". Não tenho nenhum cinismo em achar que o trabalho não vale a pena. Creio que vale a pena compreender melhor o mundo. Eu gostaria de descobrir uma vacina que curasse a maioria dos jovens ou os tirasse da pobreza. Preferiria isso. Mas, quando estou numa mesa com estudantes, [tenho que dizer que] creio que tem valor compreender melhor o mundo. Esta é a parte de sermão que lhes estou dando... Isso não é uma justificação post hoc, porque estou fazendo isso e tenho que dizer isso. Acho que, assim como um grande diretor de cinema compreende melhor o mundo, nós podemos ajudar outros a compreenderem melhor, mas isso é agora.

O problema é que, agora, há tantas possibilidades de ajudar e não posso. São tantas coisas que me pedem para fazer, e não posso, porque morreria. Então, tenho que selecionar muito cuidadosamente o que faço e o que não faço. Tenho limites, que não consigo ultrapassar. Entretanto, digo sempre a meus alunos: é possível permanecer humano e estar em uma grande universidade. Ou seja, podemos trabalhar com seriedade, formar e apoiar estudantes, sem para tal deixar de cultivar os vínculos familiares.

Enfim, a esta altura da vida, é bom poder comunicar como é o processo pelo qual passamos, que é verdadeiramente tão misterioso. Isso porque o que se vê é a 
obra completa, terminada, publicada, como se tudo tivesse sido planejado desde o início... São as aventuras da pesquisa. E isso é importante!

\section{Referências Bibliográficas}

Bandelj, Nina; Wherry, Frederick F.; Zelizer, Viviana A. (eds.). (2017), Money talks: explaining how money really works. Princeton, Princeton University Press.

; Morgan, Paul James \& Sowers, Elizabeth. (2015), "Hostile worlds or connected lives? Research on the interplay between intimacy and economy". Sociological Compass, 9 (2): 115-127.

Black, Henry C. (1968), Black's law dictionary. St. Paul, mN, West.

Block, Fred L. \& Somers, Margaret R. (2014), The power of market fundamentalism: Karl Polanyis critique. Cambridge, EUA, Harvard University Press.

Fine, B. \& Lapavitsas, C. (2000), "Markets and money in social theory: what role for economics?". Economy and Society, 29 (3): 357-382.

GARCíA, Alfredo. (2014), "Relational work in economic sociology: a Review and Extension". Sociological Compass. 8 (6): 639-647. Disponível em http://onlinelibrary.wiley.com/ doi/10.1111/soc4.12181/full, consultado em 12/1/2017.

Posner, Richard A. (1972), Economic analysis of law. Boston, Little/Brown.

Søland, Birgitte \& BRUCE, Emily (orgs.). (2012), "Pricing the Priceless Child: a retrospective”. Journal of the History of Childhood and Youth, 3 (5): 445-484.

Tavory, Iddo \& Poulin, Michelle. (2012), "Sex work and the construction of intimacy: meanings and work pragmatics in rural Malawi". Theory and Society, 41 (3): 211-231.

Tilly, Charles (1996), "Invisible elbow". Sociological Forum, 11 (4): 589-601.

TORREs, Jennifer (2015), "Expertise and sliding scales: lactation consultants, doulas, and the relational work of breastfeeding and labor support". Gender \& Society. 29 (2): 244-264.

ZeLIzer, Viviana. (1979), Morals and markets: the development of life insurance in the United States. Nova York, Columbia University Press.

. (1985), Pricing the priceless child: the changing social value of children. Princeton, Princeton University Press.

. (1989), "The social meaning of money: 'special monies". American Journal of Sociology, 95 (2): 342-377.

. (1994), The social meaning of money: pin money, paychecks, poor relief, and other currencies. Nova York, Basic Books

. (2005), La signification sociale de l'argent. Trad. Christian Cler. Paris, Seuil. (2000), "The purchase of intimacy". Law \& Social Inquiry, 25: 817-48.

(2009), "Intimacy in economic organizations". In: BANDELJ, Nina (org.). Economic sociology of work. Bingley, Emerald Group Publishing Limited, pp. 23-55. 
. (2010), Economic lives: how culture shapes the economy. Princeton, Princeton University Press. . (2012), "How I became a relational economic sociologist and what does that mean?".

Politics \& Society, Dossiê "Relational work in market economies", editado por Fred Block, 40: 145-174.

Texto enviado e aprovado em 14/1/2017. DoI: 10.11606/0103-2070.ts.2017.125519.

Viviana a. Rotman zelizer é professora no Departamento de Sociologia de Princeton University, onde ocupa a cátedra “Lloyd Cotsen '50”. E-mail: vzelizer@Princeton.edu. NADYA ARAUjo guimarães é professora titular do Departamento de Sociologia da Faculdade de Filosofia, Letras e Ciências Humanas da Universidade de São Paulo e pesquisadora I-A do CNPq associada ao Centro de Estudos da Metrópole/Cebrap.E-mail: nadya@usp.br. ANDRÉ VERETA-NAHOUM é pesquisador de pós-doutorado Fapesp (Processo n. 2014/13285-6) no Centro Brasileiro de Análise e Planejamento (Cebrap) e pesquisador associado ao Núcleo de Estudos em Cultura e Economia da Universidade Federal do Rio de Janeiro (NuCEC -UfRJ). E-mail: andre.nahoum@gmail.com.

federico Neiburg é professor do Programa de Pós-graduação em Antropologia Social, do Museu Nacional, Universidade Federal do Rio de Janeiro, Pesquisador 1в do CNPq e Coordenador do Núcleo de Pesquisas em Cultura e Economia (NuCEC).E-mail: fedrico.neiburg@gmail.com. BIANCA FREIRE-MEDEIROS é professora do Departamento de Sociologia da Faculdade de Filosofia, Letras e Ciências Humanas da Universidade de São Paulo e coordenadora do UrbanData - Brasil: Banco de Dados sobre o Brasil Urbano.E-mail: bfreiremedeiros@gmail.com. 